\title{
Pericardial effusion after open heart surgery
}

The clinical significance, natural history, and management of pericardial effusion after open heart surgery have received scant attention in published papers. Late cardiac tamponade occurs in $0 \cdot 7-3 \%$ of patients ${ }^{1-7}$ five days or more after surgery and represents the most serious complication of a postoperative effusion; the resulting deaths are due mainly to missed or delayed diagnosis. Few studies have considered whether lesser degrees of effusion have any influence on postoperative morbidity and functional recovery. ${ }^{1-6}$

The aetiology of postoperative pericardial effusion remains unclear. Initial retrospective studies suggested that anticoagulant treatment may be a cause ${ }^{89}$ but this was not supported by subsequent prospective studies. ${ }^{1-3} \mathrm{Al}-$ though no particular surgical procedure has been shown to be more commonly associated with effusion, ${ }^{1246}$ a higher incidence has been reported with the use of the internal mammary artery in coronary artery bypass grafting. Closure of the pericardium ${ }^{1210}$ and duration of chest drainage $^{11}$ do not appear to influence either the incidence or the degree of effusion. The use of a single anterior mediastinal drain tube, however, as opposed to the use of both anterior and posterior tubes, is associated with a significantly higher incidence of effusion and subsequent late tamponade. ${ }^{2}$ An association between early effusions and the postpericardiotomy syndrome has also been tentatively suggested. ${ }^{12}$ But because the features of this syndrome-malaise, anorexia, fever, and pericardial rubare rather non-specific, such an association is at best unproved.

Although chest radiography may show an increase in the size of the cardiac silhouette with a large effusion, ${ }^{5}$ it is unable to detect lesser degrees of effusion accurately. ${ }^{13}$ Two dimensional echocardiography is the technique of choice for the diagnosis of pericardial effusion..$^{1314}$ In addition to providing precise anatomical information about the distribution and amount of pericardial fluid, it may supply haemodynamic data that suggest the presence of tamponade. The reported incidence of effusion after open heart surgery has ranged from $5 \%$ to $85^{\circ} \%{ }^{1-6}$ Such variation is due to differences in the selection of patients and in the echocardiographic criteria used to define an effusion. Where echocardiography was carried out only in patients with a radiographically enlarged cardiac silhouette or clinical suspicion of tamponade, the incidence of effusion was reported to be $5 \%$ of the total patient population. ${ }^{5}$ In contrast, where all patients were studied echocardiographically and any fluid causing pericardial separation of $5 \mathrm{~mm}$ or more was regarded as an effusion the reported incidence has varied from $35^{\circ}$ o to $70 \%,{ }^{1-4}$ with a $53^{\circ}{ }_{0}$ incidence in children. ${ }^{12}$ Serial echocardiography has shown that most effusions are present by the fifth postoperative day, reaching a maximum at 10 days. ${ }^{6}$ The late natural history of effusion is, however, poorly characterised. Some authors have suggested a tendency to spontaneous resolution, ${ }^{16}$ but there are insufficient prospective data to support this statement. Effusions have persisted for as long as 28 months after cardiac surgery. ${ }^{10}$ Evidence on the association between clinical symptoms and signs and the presence of postoperative effusion is conflicting. Attempts to correlate the presence of effusion with non- incisional chest pain, ${ }^{24}$ persistent pyrexia, ${ }^{23}$ and pericardial $\mathrm{rub}^{1-4}$ have produced discordant results and such features cannot be regarded as useful predictors of the presence of effusion.

There is little doubt that postoperative pericardial effusion is associated with appreciable morbidity. Patients with pericardial effusion have been shown to have an increased incidence of postoperative supraventricular arrhythmias in four prospective studies, ${ }^{1-35}$ more median sternotomy dehiscence, ${ }^{2}$ a longer hospital stay, ${ }^{2}$ a reduced exercise tolerance, and a worse New York Heart Association class after surgery. ${ }^{310}$

Indications for treatment are at present limited to those patients in whom the effusion is causing haemodynamic embarrassment. We also advocate the drainage of effusions in patients with supraventricular arrhythmias resistant to direct current cardioversion and the usual pharmacological intervention. ${ }^{16}$ Pericardiocentesis either with fluoroscopic or echocardiographic control should be the initial approach of choice and is successful in most cases..$^{517}$ In the presence of loculated effusion or blood clot pericardiocentesis may be unsuccessful and open drainage, either by a limited subxiphoid approach or by a repeat sternotomy, may be required. ${ }^{5717}$

Thus pericardial effusion after open heart surgery is common and easily detected by two dimensional echocardiography. Effusion may persist for many months after operation. Late cardiac tamponade, the most serious complication, is rare. Lesser degrees of effusion are associated with an increased incidence of postoperative supraventricular arrhythmias, sternotomy wound dehiscence, prolonged hospital stay, and impaired functional recovery.

AJ BRYAN

Department of Cardiac Surgery, University Hospital of Wales, Cardiff

GD ANGELINI

Department of Cardiac Surgery, Northern General Hospital, Sheffield

Address for reprint requests: Mr GD Angelini, Northern General Hospital, Sheffield S5 7AU.

1 Ikaheimo MJ, Huikuri HV, Airaksinen EJ, et al. Pericardial effusion after cardiac surgery; incidence, relation to the type of surgery, anti-thrombotic therapy and early coronary bypass graft patency. Am Heart $J$ 1988;116: 97-102

2 Angelini GD, Penny WJ, El-Chamary F, et al. The incidence and sig nificance of early pericardial effusion after open heart surgery. Eur $J$ Cardiothorac Surg 1987;1:165-8.

3 Reifart N, Blumschein A, Sarai K, Bussmann WD, Satter P. Perikardergusse nach Herzoperationen. Dtsch Med Wochenschr 1985;110:1191-4.

4 Stevenson LW, Child JS, Laks H, Kern L. Incidence and significance of early pericardial effusions after cardiac surgery. $\mathrm{Am} \mathrm{J}$ Cardio $1984 ; 54: 848-51$.

5 Borkon AM, Schaff MV, Gardner JJ, et al. Diagnosis and management of post-operative pericardial effusions and late cardiac tamponade following open heart surgery. Ann Thorac Surg 1981;31:512-9.

6 Weitzmann L B, Tinker WP, Kronzon I, Cohen ML, Glassman E, Spencer FC The incidencen and surgery-an echocardiographic study. Circulation 1983;69:506-11.

7 Solem JO, Kugelberg J, Stahl E, Olim C. Late cardiac tamponade following open heart surgery: diagnosis and treatment. Scand J Thorac Cardiovasc open heart surgery: diag

8 Hochberg MS, Merrill WH, Gruber M, McIntosh CL, Henry WL, Morrow 
AG. Delayed cardiac tamponade associated with prophylactic anticoagulation in patients undergoing coronry bypass grafting. $J$ Thorac Cardiovasc Surg 1978;75:777-81

9 Merrill W, Donahoo JS, Brawley RK, Taylor D. Late tamponade: a potentially lethal complication of open heart surgery. $J$ Thorac Cardiovasc Surg 1976;72:929-32.

10 Fraser AG, Ikram S, Bryan AJ, Angelini GD. Unsuspected pericardial effusion at long term follow-up after open heart surgery. Int J Cardiac Imaging 1989;4:71.

11 Smulders YM, Wiepking ME, Moulijn AC, Koolen JJ, van Wezel HB, Visser CA. How soon should drainage tubes be removed after cardiac operations? Ann Thorac Surg 1989;48:540-3.

12 Clapp SK, Garson A Jr, Gutgesell HP, Cooley DA, McNamara DG.
Post-operative pericardial effusion and its relationship to the postpericardiotomy syndrome. Pediatrics 1980;66:585-8.

13 Martin RP, Rakowski H, French J, Popp RL. Localisation of pericardial effusion with wide angle phased array echocardiography. Am J Cardiol $1978 ; 42 \cdot 904-12$

14 Chambers JB, Monaghan MJ, Jackson G. Echocardiography: information on morphology and function. Br Med J 1988;297:1071-6.

15 Angelini GD, Bryan AJ, Lamarra M. Refractory supraventricular arrhythmias due to early posterior pericardial effusion following open heart

surgery. Thorac Cardiovasc Surgeon 1988;36:162-4.
16 Bortolotti U, Livi U, Frugoni C, et al. Delayed cardiac tamponade following open heart surgery. Analysis of 12 patients. Thorac Cardiovasc Surgeon 1981;29:233-6. 